\title{
Flexural bond strength of natural hydraulic lime mortar and clay brick
}

\author{
S. Pavía $\cdot$ R. Hanley
}

Received: 12 November 2008/ Accepted: 14 October 2009/Published online: 5 November 2009

(C) The Author(s) 2009. This article is published with open access at Springerlink.com

\begin{abstract}
This paper measures the bond strength of natural hydraulic-lime (NHL) mortars, to further characterise their properties and enhance their use in building. An additional objective is to correlate bond strength with mortar hydraulicity, water content, workability and water retention, to develop mortars of high bond strength that would improve the quality of masonry. To this aim, the flexural bond strength of masonry, built with mortars of three hydraulic strengths-each including the water amount required to attain three specific flows $(165,185$ and $195 \mathrm{~mm}$ ), was measured with the bond wrench test. The results suggest that NHL mortars possess high water retention, and this enables a strong bond that compares well to that of Portland cement and cement/ lime mortars. The results also indicate that bond strength is not determined by the binder's hydraulic strength, but it increases proportionally to the mortar's water retention. The paper concludes that for the NHL5 mortars, the $185 \mathrm{~mm}$ flow results in the strongest bond, simultaneously providing the highest water retention and best workability. However, for the lower strengths (NHL 2 and NHL 3.5 mortars), the water content required to attain the flows that
\end{abstract}

S. Pavía $(\bowtie) \cdot$ R. Hanley

Department of Civil Engineering, Trinity College Dublin, Dublin 2, Ireland

e-mail: pavias@tcd.ie

R. Hanley

e-mail: ryan.hanley@bain.com provide an optimum workability (165 and 165$185 \mathrm{~mm}$, respectively) does not lead to the strongest bond, but it is the highest flow values that provide the NHL2 and NHL3.5 mortars with the strongest bond and, in most instances, the highest water retention.

Keywords Flexural bond strength .

Natural hydraulic-lime mortar - Bond wrench test . Workability $\cdot$ Water retention $\cdot$ Initial flow

\section{Introduction}

Hydraulic lime mortars are increasingly used for new building. The bond strength of lime mortar masonry has not yet been quantified; however, this is one of the most important properties of the hardened mortar because it determines strength, durability and use of masonry. Bond deterioration reduces the compressive strength of a wall and can destroy its tensile or shear strength; and a defective bond can lead to water ingress and subsequent damage. Bond strength also impacts structural behaviour: mmasonry is strong in compression, however, it is weak in flexural tension, and the reason for this weakness is the bond interface between mortar and masonry [1]. As a result, allowable compressive stresses in building codes are substantially larger than allowable flexural tension stresses, and this limits the use of masonry as a structural 
element. Therefore, improvements in the bond strength would enhance use of masonry. Furthermore, structurally, masonry systems rely on a good bond in order to maintain integrity under exposure [2]: under wind suction or pressure, the masonry relies on the strength of the bond in order to transfer lateral stresses throughout masonry segments and support the flexural tensile stresses generated. Research has been undertaken into the bond strength of Portland cement and cement/lime mortars [3-6]. It is assumed by the building industry that Portland cement and cement/ lime mortars bond well with building units, whereas lime mortars, are not always considered capable of developing sufficient bond [7]. This is a misconception partially due to a lack of knowledge and insufficient research on lime-mortar bond strength. For example, outstanding research works such as the Smeaton Project [8] have identified bond strength as crucial but have not measured the property. The objective of this paper is to quantify the bond strength of natural hydraulic lime mortars of different hydraulic strengths (NHL2, 3.5 and 5), and investigate the effect of the mortars' hydraulicity, water retention and water content on the strength of the bond. Water content determines both the mortar's workability and its initial flow; these properties were also measured and correlated to the bond strength. This study contributes to better characterize natural hydraulic lime mortars in order to enhance their use in building, and establishes relationships between bond strength, hydraulicity, water content, workability and water retention. These relationships can assist the production of mortars designed to reach high bond strengths, and this would improve the quality and performance of hydraulic lime mortars in construction.

\section{Factors affecting bond strength}

Bond strength is a complex property influenced by mortar and brick properties and workmanship factors [9]. Groot [4] completed a comprehensive study on the bond between brick, cement mortars and cementlime mortars. The author considers of primary importance the dynamics of moisture transfer between brick and mortar after bricklaying (moisture and material transfer are needed to develop bond), and concludes, that the bond is determined by the binder hydration and the mortar composition at the interface. According to this, the strength of the bond is largely governed by the mortar's water retention, as this property controls both fluid transfer and the mortar's ability to resist water loss.

\subsection{Mortar's water retention}

Mortars lose water through evaporation, however, in contact with absorbent bricks, they lose water through suction. High water retention allows mortar to maintain moisture for proper curing and bonding and retain plasticity, so that bricks can be aligned and level without breaking the bond [10]. When used with lowabsorption bricks, mortars of low water retention bleed moisture, creating a layer of water at the interface that causes the brick to float thus decreasing bond.

\subsection{Workability}

Bond strength is also determined by the mortar's workability: a complete contact between mortar and brick is essential to develop bond, and the ease with which mortar spreads is dictated by the mortar's workability. Workability depends on the mortar's water content, water retention and internal friction (determined by aggregate properties, hydraulic strength of binder and mix proportions). In this research, workability was assessed by defining the mix consistency and measuring the outward flow of the fresh mortar (initial flow), and these results were related to research parameters including water retention and bond strength.

\subsection{Brick properties}

Brick properties affecting bond include surface texture and suction, and these were also determined in this study. Rough surfaces with pores are receptive to the wet mortar and increase adhesion (mortar flows into voids forming a mechanical attachment), while smooth or coated surfaces reduce bond strength [11]. In relation to suction, bond strength decreases as the brick's suction increases due to a rapid water loss from the mortar [12]. The initial rate of absorption (IRA) indicates the brick's suction: a high IRA means rapid moisture transfer from mortar to brick, and thus a weakened bond, while a low IRA could prevent the brick from absorbing enough moisture to develop a bond [11]. 


\subsection{Workmanship and curing}

Workmanship factors affecting bond strength include time interval before application, pressure, movement and curing conditions. These were taken into account when building the masonry prisms for testing. For example, the time interval between mixing and spreading the mortar and placing the brick was minimised in order to avoid water loss, however, the assembly took place in laboratory conditions, and water loss is more relevant when construction takes place in hot, dry weather. Tapping the brick unit to level can increase bond strength by $50-100 \%$ over hand pressure alone [10]; however, when using mortars of low water retention, tapping can also break the bond. In this research, pressure was applied to the bricks according to the relevant standard as specified below. With regard to movement and curing conditions, the bricks were not moved after laying as this breaks or weakens the bond, and the partially dried mortar may not have sufficient workability to re-adhere. Finally, curing conditions also influence mechanical and chemical bond [10]. The brick prisms were cured at $60-65 \%$ relative humidity.

\section{Materials and methods}

The flexural bond strength of 27 brick prisms built with nine mortars (2 $\frac{1}{2}: 1$ - aggregate: binder by weight), including different water contents required to attain specific flows (Table 1), was measured with the bond wrench test. In addition, the water content, water retention and workability of the mortars were determined, and the effect of these properties and the binder's hydraulicity on the strength of the bond investigated. The quantity of water required for the mortars to attain the flow diameters was recorded and is reported in Table 1, as a percentage of the ratio of water to the total mortar by mass, as prescribed in EN 459-2 [13]. Details on the test methods and the number of specimens tested are provided in the relevant sections below.

\subsection{Determination of water retention}

The mass of water retained by the mortar after suction, expressed as a percentage of the original water content, was measured according to EN 4551 [14]. A mould was filled with mortar and cotton gauze, a filter paper plate and a non-porous plate followed by a 2-kg weight placed over. After $2 \mathrm{~min}$, the filter paper mass was recorded. Three readings were taken from each mix and three mixes tested for each lime strength class mixed to a given flow, therefore the results are based on 81 readings taken from 27 mortars. The water fraction of the mortar batch $\left(W_{1}\right)$ was calculated using Eq. 1 below:

$W_{1}=\frac{m_{8}}{m_{8}+m_{9}}$

where:

$m_{8}$ is the total mass of water in fresh mortar batch, (g);

$m_{9}$ is the mass of the dry mortar batch, $(\mathrm{g})$

The water content of the mortar $\left(W_{2}\right)$ was quantified, according to the standard, using the masses of mortar, moulds and plates, and the water fraction of the mortar batch $\left(W_{1}\right)$. Finally, the mass of water absorbed by the filter plate $\left(W_{3}\right)$ was calculated using the mass of the dry and soaked filter plates, and the water retention $(W R V)$ evaluated according to Eq. 2 below:

$W R V=\frac{W_{2}-W_{3}}{W_{2}} \times 100 \%$

\subsection{Water content, initial flow and workability}

Water content determines both the mortar's workability and its initial flow. These three parameters were estimated. Workability, as a characteristic often defined by the mason, was qualitatively assessed by describing the mix consistency. In addition, workability was characterized by measuring the initial flow of the mortars according to EN 459-2 [13]. The lime binders were mixed with the appropriate amount of water to attain three specific flow values: 165,185 and $195 \mathrm{~mm}$ diameters (selected based on EN 459-2 and Hanley and Pavía [15]), and the amount of water required for each mortar mix in order to reach the prescribed flow noted. In order to determine the initial flow, a truncated cone mould was placed on the flow table and filled with mortar. The mould was then lifted and the table raised $10-\mathrm{mm}$ and dropped at a rate of once per second for $15 \mathrm{~s}$. The final diameter of the mortar (initial flow) was measured in millimeters. The quantity of water required for the mortars to attain 
Table 1 Water content (mean of three mixes), water retention (mean of nine readings), initial flow and workability of NHL mortars of different hydraulic strengths; amortar mixed to reach an initial flow of $165 \mathrm{~mm}$; b$185 \mathrm{~mm}$; c-195 mm

\begin{tabular}{lllll}
\hline $\begin{array}{l}\text { Mix by } \\
\text { binder }\end{array}$ & $\begin{array}{l}\text { Initial flow } \\
(\mathrm{mm})\end{array}$ & $\begin{array}{l}\text { Water } \\
\text { content }(\%)\end{array}$ & $\begin{array}{l}\text { Water retention } \\
(\%)\end{array}$ & Qualitative workability assessment \\
\hline NHL2a & 165 & 17.1 & 96.3 & Good consistency,easy to work with \\
NHL2b & 185 & 18.5 & 97.6 & Quite fluid,hard to work with \\
NHL2c & 195 & 18.7 & 99.5 & Extremely fluid, very difficult to work with \\
NHL3.5a & 165 & 13.0 & 94.3 & Slightly dry \\
NHL3.5b & 185 & 15.4 & 93.2 & Slightly fluid \\
NHL3.5c & 195 & 15.7 & 94.2 & Quite fluid, hard to work with \\
NHL5a & 165 & 14.9 & 94.6 & Slightly dry \\
NHL5b & 185 & 15.8 & 95.1 & Good consistency,easy to work with \\
NHL5c & 195 & 17.0 & 94.2 & Slightly fluid \\
\hline
\end{tabular}

the flow diameters was recorded and is reported as the ratio of water to lime binder in Table 1 .

\subsection{Determination of flexural bond strength: the bond wrench test}

The bond wrench test determines the flexural bond strength of masonry by subjecting a masonry prism to an eccentric load which 'wrenches' the top brick from the rest of the assembly, allowing to test several mortar joints in a single prism. Loads, applied through a cantilevered arm, induce tension over half the mortar joint and compression over the other half. This test was carried out according to EN 1052-5 [16] incorporating modifications from McGinley [17] to reduce concentrations and non-linear distributions of stresses during loading, and enhance validity of results. Modifications include reducing the rotation of the upper clamp, increasing the stiffness of the apparatus, ensuring that the lower section of the prism is not loaded during testing and applying a low and uniform loading rate.

Three prisms of six bricks each were assembled in the laboratory with each of the nine mortar types in Table 6 , thus 135 bond strength measurements were carried out (15 for each mortar type). The prisms were assembled on a plywood pallet, and the pallet and brick faces aligned with levels. A mortar joint template ensured consistent joint thickness of $12 \mathrm{~mm}$ before tamping (Fig. 1). The bricks were tamped with a $1.0 \mathrm{~kg}$ hammer as prescribed by the standard. The prisms were covered with damp hessian sac and cured for 28 days.

After curing, the lower clamping vice and upper clamping bracket were tightened to the second and

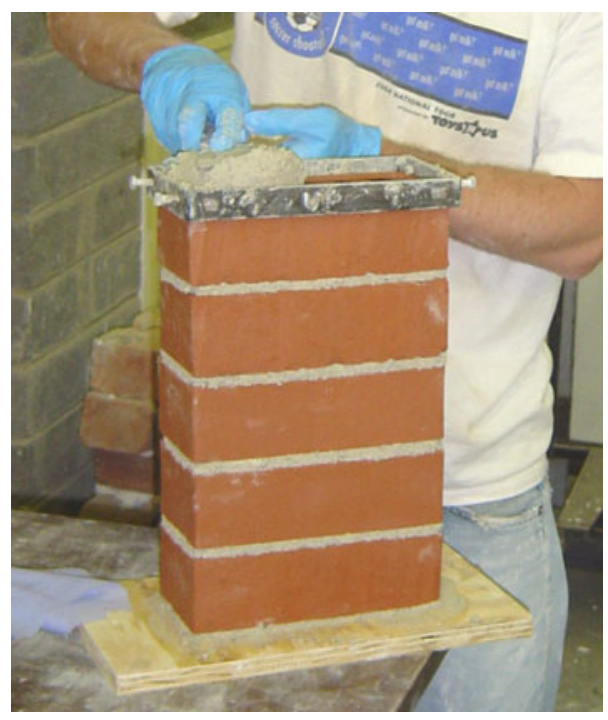

Fig. 1 Prism assembly with mortar joint template

top brick, respectively. The load was then applied incrementally by adding weights to the extension arm. Following failure, the brackets were removed and the prism risen in order to test the next joint. Figure 2 shows the bond wrench apparatus with a prism in place and weights applied to the loading arm.

The flexural bond strength was calculated using Eq. 3 below:

$F_{n}=\frac{\left(P L+P_{1} L_{1}\right)}{S}-\frac{\left(P+P_{1}\right)}{A}$

where:

$\mathrm{F}_{\mathrm{n}}=$ net area flexural tensile strength (MPa),

$\mathrm{P}=$ maximum machine applied load $(\mathrm{N})$, 


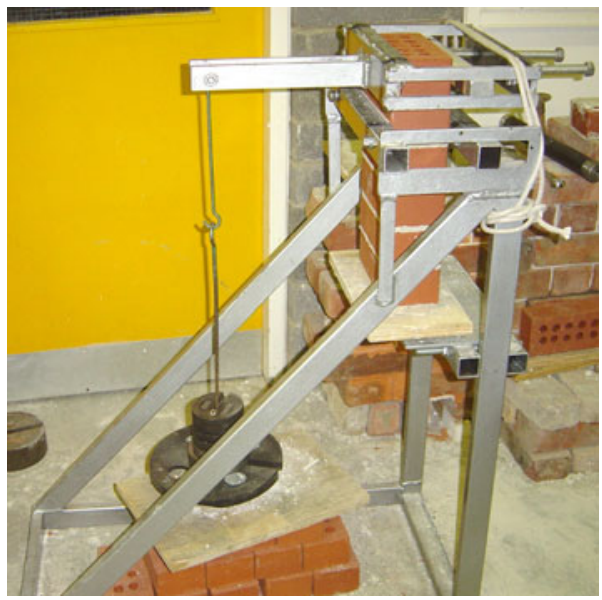

Fig. 2 Bond wrench testing apparatus

$\mathrm{P} 1=$ weight of loading arm and brick unit $(\mathrm{N})$

$\mathrm{L}=$ distance from center of prism to loading point (mm),

$\mathrm{L} 1=$ distance from center of prism to centroid of loading arm (mm)

$\mathrm{S}=$ section modulus of actual net bedded area $\left(\mathrm{mm}^{3}\right)$,

$\mathrm{A}=$ net bedded area $\left(\mathrm{mm}^{2}\right)$.

\subsection{Determination of brick properties}

Brick properties including initial rate of absorption, compressive strength, net bedded area, volume, moment of inertia, dry mass and section modulus were calculated according to EN 772, parts 1 and 16 $[18,19]$. Perforated, extruded, clay brick of dimensions $67 \times 218 \times 104 \mathrm{~mm}$, featuring ten vertical cores of $10.7 \mathrm{~mm}$ radius were used for testing. The mean value of six specimens and the coefficient of variance were calculated. Additionally, in order to measure the flexural bond strength, the section modulus $\left(S\right.$ in $\left.\mathrm{mm}^{3}\right)$ and second moment of inertia were estimated using Eq. 4 below:

$S=\frac{I}{c}$

where:

$I \quad$ is the second moment of inertia, $\left(\mathrm{mm}^{4}\right)$

$c$ is the distance from the centroid to the extreme edge of the brick (mm)
Accounting for the 10 cores and incorporating the Parallel-axis theorem, the moment of inertia for the brick is found using Eqs. 5 and 6 below:

$I=\int_{A} y^{2} d A$

$I_{x}=\frac{b h^{3}}{12}-10\left(\frac{\pi r^{4}}{12}+\pi r^{2} d^{2}\right)$

where:

$I_{x}$ is the second moment of inertia of the brick $\left(\mathrm{mm}^{4}\right)$

$b \quad$ is the width of the masonry face $(\mathrm{mm})$

$h$ is the height of the masonry face $(\mathrm{mm})$

$r$ is the radius of the circle $(\mathrm{mm})$

$d$ is the distance between the z-axis and the centroidal axis $(\mathrm{mm})$

The initial rate of absorption was calculated according to EN 772-11 [20]. To this aim, the brick's bed was immersed in a $5 \mathrm{~mm}$-deep sheet of water for $1 \mathrm{~min}$. The units were then removed and wiped, their mass was measured, and Eq. 7 below used to determine the initial rate of absorption:

$c_{w i, s}=\frac{m_{s o, s}-m_{d r y, s}}{A_{s} t} \times 10^{3}\left[\mathrm{~kg} /\left(\mathrm{m}^{2} \times \min \right)\right]$

where:

$c_{w i, s}$ is the coefficient of water absorption due to capillary action

$m_{s o, s}$ is the mass of the specimen in grams after soaking for time $\mathrm{t},(\mathrm{g})$

$m_{d r y, s}$ is the mass of the specimen after drying, (g) $\mathrm{A}_{\mathrm{s}} \quad$ is the gross area of the face of the specimen immersed in water, $\left(\mathrm{mm}^{2}\right)$

$t \quad$ is equal to $1 \mathrm{~min}$

\section{Results and discusion}
4.1 Water content, water retention, initial flow and workability

Table 1 includes the water content, water retention and workability of the NHL mortars of different hydraulic strengths, tested with variable initial flows; while Fig. 3 shows the influence of the water content, in the water retention of the NHL mortars. 
Fig. 3 Influence of water content (that needed to attain 165,185 and $195 \mathrm{~mm}$ flow diameters (df)-see Table 1) in the water retention of NHL mortars of different strengths. Each value is the mean of nine readings

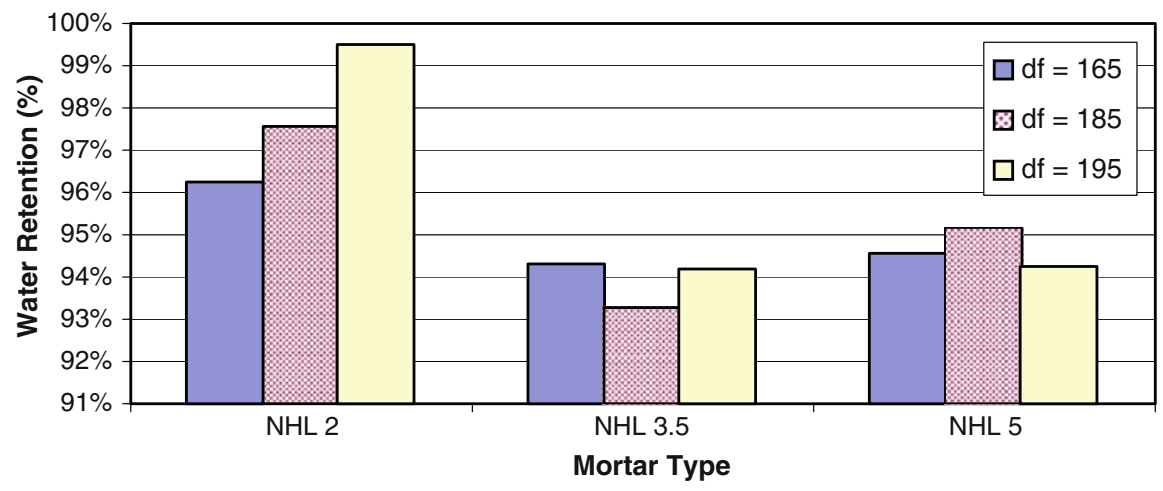

As aforementioned (see factors that determine bond strength) the bond is determined by the mortar's water retention. In addition, a complete contact between brick and mortar is essential to develop bond, and the ease with which mortar spreads and covers the brick is dictated by the mortar's initial flow and its workability.

According to the results in Table 1 and Fig. 3, the water retention of the NHL mortars is high, ranging from 94.2 to $99.5 \%$, therefore, all batches exhibit adequate values to successfully bond to absorbent bricks.

As expected, the flow rises with the water content, however, only certain flows are coupled to a good workability because too fluid mixes have little consistency and are hard to work with. It can be seen from the results that, for NHL2, the lowest flow displays the best workability whereas the flow that enhances workability for the higher hydraulic strength (NHL5) is $185 \mathrm{~mm}$ and, by linear extrapolation, the flow that provides the best workability for NHL3.5 is close to $175 \mathrm{~mm}$.

The results also evidence that the NHL2 mortars possess the highest water retention; therefore, these would retain the highest amount of water in contact with absorbent bricks. This agrees with previous authors stating that water retention increases proportionally to the percentage of free lime in the binder (H. Schiffner, IKM Köln, unpublished reports
2002-2006). NHL5 retention values are similar to those of NHL3.5, suggesting that both hydraulic strengths would behave similarly in contact with absorbent bricks.

According to the results obtained, the water retention of NHL2 mortar increases with the water content and initial flow, however, the lowest initial flow shows the best workability. This trend is not evidenced in the binders of higher hydraulic strengths, in contrast, NHL3.5 and NHL5 do not increase water retention with increasing water content and flow: the $185 \mathrm{~mm}$ flow of NHL5 mortars displays the highest water retention and the best workability while the NHL3.5 results do not evidence a specific water content (initial flow) that enhances both water retention and workability.

\subsection{Brick properties}

Table 2 includes the net bedded area, volume, moment of inertia, dry mass, compressive strength and section modulus calculated for the bricks tested; while Fig. 4 includes the water absorbed by the bricks as a function of time, and Table 3 the ratio of moisture content to the total absorption after $24 \mathrm{~h}$.

As aforementioned, the dynamics of water absorption by the masonry greatly affect bond strength: the total amount of moisture absorbed is not a central factor, however, the rate at which this moisture is

Table 2 Physical properties of the bricks tested (mean value of six specimens)

\begin{tabular}{llllll}
\hline Net bedded area $\left(\mathrm{mm}^{2}\right)$ & Volume $\left(\mathrm{mm}^{3}\right)$ & $\begin{array}{l}\text { Moment of inertia, I, } \\
\text { of net bedded area }\left(\mathrm{mm}^{4}\right)\end{array}$ & $\begin{array}{l}\text { Section modulus, } \\
\mathrm{S}=\mathrm{I} / \mathrm{c}\left(\mathrm{mm}^{3}\right)\end{array}$ & $\begin{array}{l}\text { Dry mass }(\mathrm{g}) \\
\text { Compressive } \\
\text { strength }(\mathrm{MPa})\end{array}$ \\
\hline $1.98 \times 10^{4}$ & $1.51 \times 10^{6}$ & $1.97 \times 10^{7}$ & $3.78 \times 10^{5}$ & 2347.8 & 23.1 \\
\hline
\end{tabular}


Fig. 4 Dinamics of water absorption of the brick over time. Based on mean values of six specimens
Table 3 Moisture content of the bricks as a function of time, and ratio of moisture content to the total absorption after $24 \mathrm{~h}$ (mean values of six specimens)

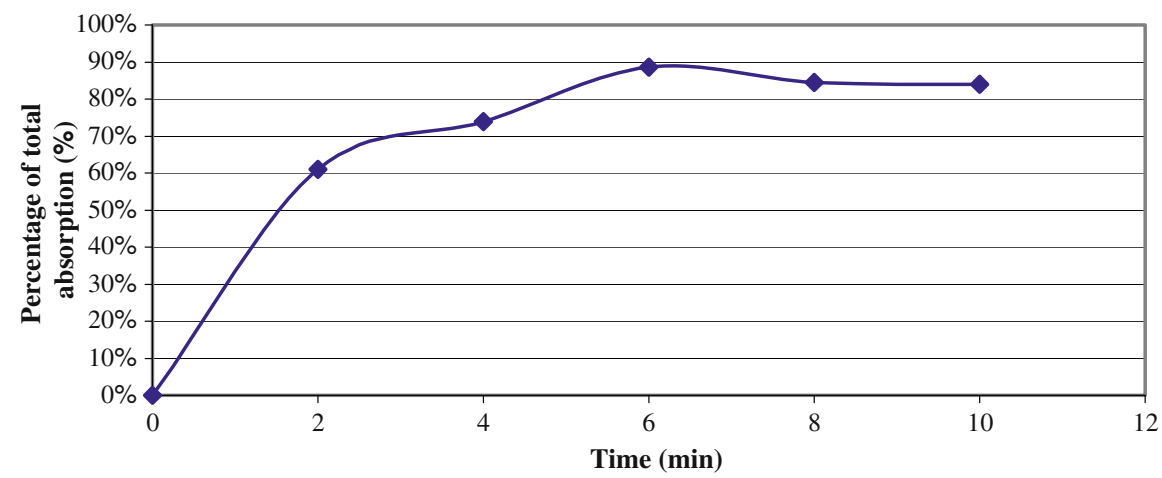

\begin{tabular}{llll}
\hline Time $(\min )$ & $\begin{array}{l}\text { Water absorbed } \\
(\mathrm{g})\end{array}$ & $\begin{array}{l}\text { Moisture content } \\
(\%)\end{array}$ & $\begin{array}{l}\text { Total 24 h } \\
\text { absorption (\%) }\end{array}$ \\
\hline 2 & 153.2 & $6.6 \%$ & $61.0 \%$ \\
4 & 185.8 & $7.9 \%$ & $73.8 \%$ \\
6 & 223.4 & $9.5 \%$ & $88.6 \%$ \\
8 & 212.4 & $9.1 \%$ & $84.4 \%$ \\
10 & 211.6 & $9.0 \%$ & $83.9 \%$ \\
$\begin{array}{l}\text { Total absorption } \\
\text { at 24 h }\end{array}$ & 252.8 & $10.7 \%$ & $100.0 \%$ \\
\hline
\end{tabular}

absorbed is. As it can be seen from Fig. 4 and Table 3, the bricks initially absorb water quickly (the rate of absorption is greatest during the first $2 \mathrm{~min}$ of immersion, reaching a moisture content of $61 \%$ of the total absorption). This agrees with the calculated initial rate of absorption (IRA) in Table 4: the mean IRA is $3.22 \mathrm{~kg} /\left(\mathrm{m}^{2} \times \mathrm{min}\right)$, a high value (clay brick IRA's usually range between 0.35 and $3.60 \mathrm{~kg} /$ $\left.\left(\mathrm{m}^{2} \times \mathrm{min}\right)\right)$ indicating that the bricks absorb water quickly. The IRA's coefficient of variation is $3.40 \%$, suggesting consistency in testing procedure and materials. According to Sinha [21] both saturated

Table 4 Initial rate of absorption of bricks (single values)

\begin{tabular}{ll}
\hline Brick specimen & IRA, $\mathrm{kg} /\left(\mathrm{m}^{2} \times \mathrm{min}\right)$ \\
\hline 1 & 3.16 \\
2 & 3.34 \\
3 & 3.25 \\
4 & 3.34 \\
5 & 3.07 \\
6 & 3.16 \\
Mean & $3.22(\mathrm{COV} \mathrm{3.40 \% )}$ \\
\hline
\end{tabular}

and dry bricks result in masonry assemblies with low bond strengths, and bond strength falls by $40-50 \%$ if the brick is dry, reaching its highest value when brick's moisture content is approximately $80 \%$ of the saturation value [6]. According to these, in order to control suction and enhance bond, the bricks were prepared for testing by $3 \mathrm{~min}$ immersion $20 \mathrm{~min}$ prior to assembly, resulting in a moisture content of approximately $70 \%$ of saturation.

\subsection{Flexural bond strength}

As it can be seen from Table 5, several failure modes occurred: $15.8 \%$ assemblies failed at the upper interface and $49.6 \%$ at the lower one, while $34.6 \%$ failed at both interfaces and none failed due to tension within the mortar. This suggests that the NHL mortars possess good cohesion, and that the interfaces are homogeneous and assembly was consistent.

Table 6 presents the average failure loads and resulting flexural bond strength of the mortars; while the variation of bond strength with respect to initial flow, hydraulic strength and water retention, is summarised in Fig. 5. 
Table 5 Percentage of test specimens exhibiting each type of failure mode (EN 1052-5)

Tension faces are identified by 1 and compression faces by 2

Table 6 Average failure loads and flexural bond strength of NHL mortars

Each entry is the mean value of 15 tests

Fig. 5 Variation of flexural bond strength with respect to initial flow $(165,185$, $195 \mathrm{~mm})$, hydraulic strength and water retention (\%)
Failure at upper brick-mortar interface

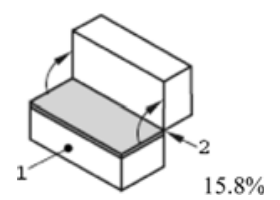

Failure at both brick-mortar interfaces

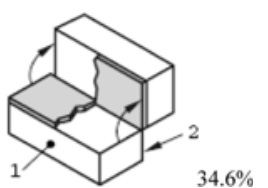

Failure at lower brick-mortar interface

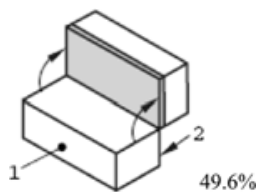

Tension failure within mortar

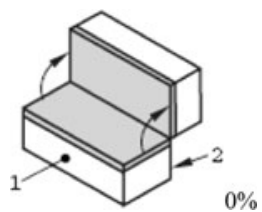

\begin{tabular}{lllll}
\hline Mix by binder & $\begin{array}{l}\text { Average failure } \\
\text { load (N) }\end{array}$ & COV (\%) & $\begin{array}{l}\text { Flexural tensile } \\
\text { strength (MPa) }\end{array}$ & COV (\%) \\
\hline NHL2a & 282.5 & 31.4 & 0.276 & 32.6 \\
NHL2b & 344.4 & 17.9 & 0.339 & 18.5 \\
NHL2c & 425.0 & 20.5 & 0.421 & 21.1 \\
NHL3.5a & 205.4 & 23.3 & 0.198 & 24.6 \\
NHL3.5b & 590.6 & 19.7 & 0.589 & 20.1 \\
NHL3.5c & 607.5 & 15.7 & 0.606 & 16.0 \\
NHL5a & 329.6 & 32.8 & 0.324 & 33.9 \\
NHL5b & 502.7 & 25.5 & 0.500 & 26.1 \\
NHL5c & 481.4 & 16.0 & 0.478 & 16.4 \\
\hline
\end{tabular}

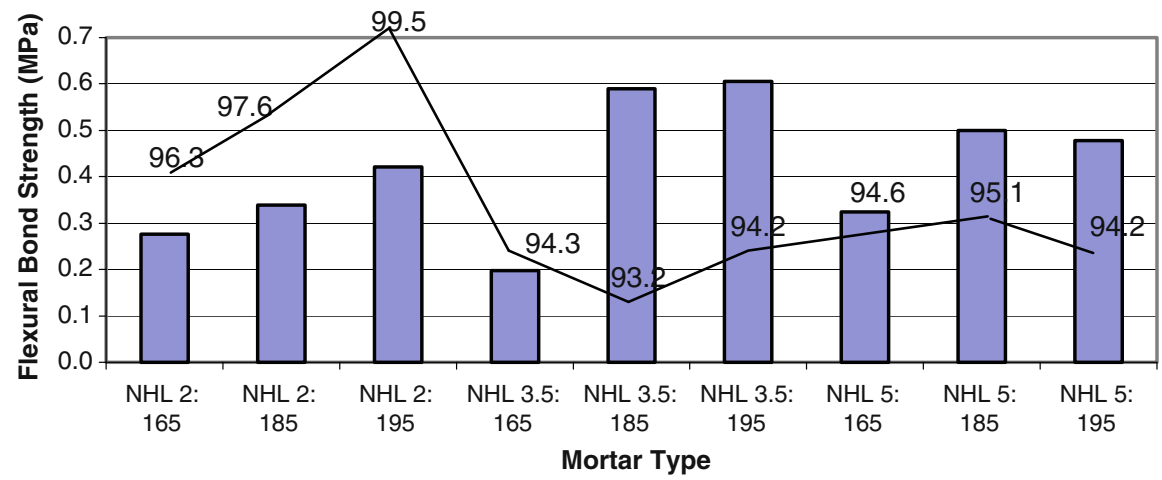

These results suggest that the strength of the bond is not determined by the hydraulic strength of the binder but tends to increase proportionally to the mortar's water retention. For example, for NHL2 and NHL5, there is a direct relationship between water retention and bond strength: the highest water 
retention results in greatest bond strength; a trend which is not maintained in the NHL3.5 mixes, however, this may relate to testing inconsistencies and requires further work (NHL3.5 and some NHL2 mixes with high initial flows often invaded brick shafts forming icicle-like extensions which may have added shear strength to the bond capacity measured).

The results also evidenced that, for NHL2 and NHL3.5 mortars, bond strength increases linearly with the initial flow, with the highest flow exhibiting the greatest strength. This suggests that, higher flows optimise bond strength. However, as aforementioned, the bond strength of the highest flows may be overestimated due to the mortar icicles in brick shafts adding capacity to the measured strength, furthermore, the fluid consistency of the $195 \mathrm{~mm}$ batches undermines application (it was clear from the workability and flow results in Table 1 that, for NHL2, the lowest initial flow $(165 \mathrm{~mm})$ possesses the best workability while for NHL3.5 the optimum value is close to $175 \mathrm{~mm}$ ). The bond strength of NHL3.5 and NHL5 mortars with the lowest initial flow is substantially lower than that provided by the higher flow values. This suggests that the lowest flow produces dry NHL3.5 and NHL5 mortars that result in inadequate adhesion. Finally, for NHL5 mortars, the $185 \mathrm{~mm}$ flow exhibits the strongest bond strength slightly decreasing for the $195 \mathrm{~mm}$ flow. This agrees with previous authors stating that tensile bond strength increases for wetter mortars but falls off when these become saturated [21]. The results also agree with Hanley and Pavía [15], who concluded that, the optimal initial flow that enhances both flexural and compressive strength simultaneously providing an appropriate level of workability is close to $165 \mathrm{~mm}$ for NHL2 mortars and close to the $185 \mathrm{~mm}$ prescribed by European standards for NHL3.5 and NHL5 mortars.

According to the results obtained, the bond strength of NHLs compares well to that of Portland cement and cement-lime mortars. E.g. the bond strength values in this research are superior to the 0.06-0.38 MPa bond strength measured on cement mortars by McGinley [22] using the wrench method, and comparable to the $0.17-0.50 \mathrm{MPa}$ bond strength results measured for cement/lime mortars by Groot [4] using the cross-couplets method.

Precision guidelines are not available for this test method. However, published data obtained under conditions almost identical to this test show coefficients of variation between 10 and $25 \%$ for Portland cement mortars [3,5]. In this research, the average $\mathrm{COV}$ for the failure loads is $22.5 \%$ and that for the flexural tensile strength $23.2 \%$. In addition, only two mortars fall substantially outside of the 10$25 \%$ range (NHL2 and NHL5 with $165 \mathrm{~mm}$ initial flow), and this may be related to inconsistencies during assembly.

\section{Conclusion}

This work concludes that NHL mortars possess a high water retention that enables successful bond with absorbent brick. Despite the bricks having a high initial rate of absorption, the bond strength values reached are high, comparable to those of Portland cement and cement/lime mixes. The conclusions below apply to masonry assembled with pre-wetted, high-suction brick.

This paper concludes that the parameter that greatest influences bond strength is water retention, followed by water content and, finally, hydraulic strength. Therefore, the strength of the bond is not determined by the hydraulic strength of the binder, as it is generally believed in many sectors of construction, rather, the bond strength of masonry is mainly governed by the mortar's water retention: the higher the water retention the strongest the bond.

The results have also evidenced that NHL2 mortars are capable of retaining the highest amount of water when in contact with absorbent brick, therefore maintaining moisture for proper curing and bonding and retaining plasticity for longer periods, so that bricks can be aligned or levelled without breaking the bond. In contrast, the higher hydraulic strengths (NHL3.5 and NHL5) retain less water, behaving similarly in contact with absorbent bricks.

This paper has established relationships between water retention, initial flow (workability) and bond strength of NHL mortars. The water content responsible for the flow that provides an optimum workability (165 mm for the NHL2; between 165 and $185 \mathrm{~mm}$ for the NHL3.5 and $185 \mathrm{~mm}$ for the higher hydraulic strength) not always provides the greatest bond strength: for the lower hydraulic strengths, the higher the flow the stronger the bond whereas for the NHL5, the medium flow value $(185 \mathrm{~mm})$ results in the strongest bond simultaneously providing the 
highest water retention and best workability. The water content required for the NHL 2 and NHL 3.5 mortars to attain the flows that provide an optimum workability (165 and $165-185 \mathrm{~mm}$, respectively) does not lead to the strongest bond, but it is the highest flow values that provide the NHL2 and NHL3.5 mortars with the strongest bond and, in most instances, the highest water retention.

Based on these relationships, the paper concludes that, in order to optimise bond strength, mortars should be mixed to the maximum initial flow that still yields an adequate workability, and that, for NHL2, this optimal flow is close to $165 \mathrm{~mm}$; for NHL3.5 slightly below $185 \mathrm{~mm}$, and for NHL5 it equals $185 \mathrm{~mm}$. These flows are coupled to high water retention and result in strong flexural bond.

The results also suggest that bond strength is adversely affected to a greater extent when mortars are too dry rather than too wet: mortars that are too wet to be workable still exhibit good bond strength whereas dry mixes exhibit significantly lower bond strength. Therefore, if doubt exists about the level of workability needed to ensure bond strength, higher water/binder ratios should be preferred.

Acknowledgments This research was funded by the US-Ireland Alliance under the G. J. Mitchell Scholarship 2004-2005. Materials were donated by St Astier, France, The Traditional Lime Company, Ireland, and Otterbein, Germany. The authors thank Laurent Tedeschi, Pierre Bergoin, Edward Byrne and Uwe Stingl for providing the materials. The testing was carried out in the Department of Civil, Structural and Environmental Engineering, Trinity College Dublin. The authors thank Mr. Dave McAuley for his building of equipment; Chief Technician Mr. Chris O'Donovan, for facilitating our laboratory work and Mr. Eoin Dunne for his assistance with testing.

Open Access This article is distributed under the terms of the Creative Commons Attribution Noncommercial License which permits any noncommercial use, distribution, and reproduction in any medium, provided the original author(s) and source are credited.

\section{References}

1. Colville J, Made AM, Miltenberger M (1999) Tensile bond strength of polymer modified mortar. J Mat Civil Eng 11:1-5

2. Portland Cement Association (PCA) (1994) Bond strength testing of masonry. Masonry Information, Skokie, Illinois
3. Hedstrom EG, Tarhini KM, Thomas RD et al (1991) Flexural bond strength of concrete masonry prisms using portland cement and hydrated lime mortars. Mason Soc J $9(2): 8-23$

4. Groot C (1993) Effects of water on mortar brick bond. University of Delft, The Netherlands

5. Melander JM, Ghosh SK, Dubovoy VS et al (1993) Flexural bond strength of concrete masonry prisms using masonry cement mortars. In: Masonry: design and construction, problems and repair. ASTM STP 1180, Philadelphia, pp 152-164

6. Venumadhava Rao K, Venkatarama Reddy BV, Jagadish KS (1996) Flexural bond strength of masonry using various blocks and mortars. Mater Struct 29:119-124

7. Gabby B (2004) Hydraulic lime mortars. Simpson Gumpertz \& Heger, Boston

8. Teutonico JM, McCaig I, Burns C, Ashurst J (1994) The smeaton project: factors affecting the properties of limebased mortars. APT XXV:32-49

9. Hendry AW, Khalaf FM (2001) Masonry wall construction. E \& FN Spon, London

10. Masonry Advisory Council (MAC) (2004) Mortars. Masonry Technical Library, Illinois

11. The Brick Industry Association (BIA) (2003) Mortars for brick masonry. Technical notes on Brick Construction, Reston, Virginia

12. US Army (2005) Masonry structural design for buildings. Joint Departments US Army, Navy \& Air Force, Washington, DC

13. EN 459-2 (2001) Building lime, part 2: test methods. European Committee for Standardisation CEN, Brussels

14. EN 4551 (2005) Methods of test for mortar. Chemical analysis and physical testing. European Committee for Standardisation CEN, Brussels

15. Hanley R, Pavía S (2008) A study of the workability of natural hydraulic lime mortars and its influence on strength. Mater Struct 4(2):373-381

16. EN 1052-5 (2005) Methods of test for masonry, part 5: determination of bond strength by the bond wrench method. European Committee for Standardisation CEN, Brussels

17. McGinley WM (1993) Flexural bond strength testing-an evaluation of the bond wrench testing procedures. In: Masonry: design and construction, problems and repair. ASTM STP 1180, Philadelphia, pp 213-227

18. EN 772-1 (2000) Methods of test for bricks, part 1: determination of compressive strength. European Committee for Standardisation CEN, Brussels

19. EN 772-16 (2000) Methods of test for bricks, part 16 : determination of dimensions. European Committee for Standardisation CEN, Brussels

20. EN 772-11 (2000) Methods of test for bricks, part 11: determination of water absorption of aggregate concrete, manufactured stone and natural stone bricks due to capillary action and the initial rate of water absorption of clay bricks. European Committee for Standardisation CEN, Brussels

21. Sinha BP (1967) Model studies relating to load bearing brickwork. PhD thesis, University of Edinburgh, UK

22. McGinley WM (1990) IRA and the flexural strength of clay brick masonry. In: Masonry-components to assamblages. ASTM STP 1063, Philadelphia, pp 217-235 